\title{
Association between Latitude and Breast Cancer Incidence in Mainland Australian Women
}

\author{
Kellie Bilinski, ${ }^{1}$ Karen Byth, ${ }^{2}$ and John Boyages ${ }^{3}$ \\ ${ }^{1}$ The Children's Hospital at Westmead and The University of Sydney, Locked Bag 4001, Westmead, NSW 2145, Australia \\ ${ }^{2}$ SWAHS Research Network and The University of Sydney, P.O. Box 143, Westmead, NSW 2145, Australia \\ ${ }^{3}$ Macquarie University Cancer Institute (MCI) and Australian School of Advanced Medicine (ASAM), Macquarie University, \\ 2 Technology Place, NSW 2109, Australia
}

Correspondence should be addressed to Kellie Bilinski; kellie.bilinski@me.com

Received 22 August 2014; Revised 2 November 2014; Accepted 10 November 2014; Published 9 December 2014

Academic Editor: Ruth O’Regan

Copyright (C) 2014 Kellie Bilinski et al. This is an open access article distributed under the Creative Commons Attribution License, which permits unrestricted use, distribution, and reproduction in any medium, provided the original work is properly cited.

\begin{abstract}
Aim. To investigate whether breast cancer incidence increases with increasing latitude in mainland Australian women. Methods. A cross-sectional study of female breast cancer and cutaneous melanoma incidence 2002-2006 by 5-year age group and local government area. Latitude, Accessibility/Remoteness Index of Australia (ARIA), and Index of Relative Socioeconomic Disadvantage (IRSD) were assigned to local government areas. Latitude was grouped into bands $\left(\leq 27^{\circ} \mathrm{S} ;>27-30^{\circ} \mathrm{S} ;>30-33^{\circ} \mathrm{S} ;>33-36^{\circ} \mathrm{S}\right.$, and $>36^{\circ} \mathrm{S}$ ), and IRSD was divided into quintiles and ARIA into four categories. Breast cancer rates were age standardized using the direct method. The joint effects of latitude, age, IRSD, and ARIA on incidence of breast cancer and cutaneous melanoma were assessed using multiple logistic regressions. Results. At latitudes south of $30^{\circ} \mathrm{S}$, rates of breast cancer were over double that north of $27^{\circ} \mathrm{S}$ (76.4 versus 160.2-176.5). Age-adjusted odds ratios of breast cancer were increased in all latitudes south of $30^{\circ} \mathrm{S}$ compared with north of $27^{\circ} \mathrm{S}$ within each IRSD and ARIA category (all $P<0.001$ ). After adjusting for age, IRSD, and ARIA, the odds ratio of breast cancer south of $30^{\circ} \mathrm{S}$ was 1.92 (95\% CI 1.84-2.09; $\left.P<0.001\right)$, whereas cutaneous melanoma was 0.65 (95\% CI 0.61-0.68; $P<0.001)$ times north of $30^{\circ} \mathrm{S}$. Discussion. Increasing latitude is positively associated with breast cancer and negatively associated with cutaneous melanoma incidence. These findings support suggestions that increased risk of breast cancer might be explained by lower ultraviolet radiation-induced vitamin D synthesis.
\end{abstract}

\section{Introduction}

Ecologic studies show that the incidence and mortality of breast cancer increase from the equator (latitude $0^{\circ}$ ) as latitude increases towards the earth's poles $\left(90^{\circ}\right)[1-3]$. Similarly, the rates of breast cancer have been shown to be inversely associated with the level of ultraviolet (UV) radiation from sunlight [4-9].

For most individuals, solar UV radiation in the B spectrum is the primary source of vitamin D [10]. Exposure of the skin to UV radiation between the wavelengths of 290 and $330 \mathrm{~nm}$ causes photolysis of 7-dehydrocholesterol to form previtamin $\mathrm{D}_{3}$. In a heat-induced process, previtamin $\mathrm{D}_{3}$ is then converted to vitamin $\mathrm{D}_{3}$, which is subsequently hydroxylated in the liver and the kidneys or in local tissue such as breast, to form the active form of the vitamin, 25hydroxyvitamin $\mathrm{D}_{3}[10]$.

Geographic latitude is an important determinant of cutaneous vitamin $\mathrm{D}$ synthesis, as it influences the amount of UV radiation reaching the skin [11]. An increase in latitude causes the solar zenith angle, the angle between the earth's local vertical and the position of the sun at a given moment, to increase. At the equator, the solar zenith angle is at its smallest. The solar zenith angle increases as latitude increases towards the poles, thereby increasing the path that sunlight is required to travel through the atmosphere towards the earth. This results in increased UV scatter and absorption, subsequently reducing the amount of UV radiation that reaches the earth's surface. It follows that the higher UV radiation levels at lower latitudes (closer to the equator) 
increase the potential for vitamin D synthesis, compared with the lower UV radiation levels occurring at higher latitudes (further away from the equator), where the potential for vitamin $\mathrm{D}$ synthesis is reduced. Although there is little data comparing vitamin $\mathrm{D}$ levels according to location in Australia, findings from a 2012 study were consistent with this hypothesis, which showed that vitamin $\mathrm{D}$ deficiency is more common in individuals residing south of $30^{\circ} \mathrm{S}$ in comparison to those closer to the equator [12]. Similarly, we have previously shown that in the winter months when the solar zenith angle is greater there is a higher prevalence of vitamin D deficiency [13].

The first suggestion that sunlight exposure may lower the risk of cancer was first made by Peller and Stephenson in 1937 [14], after which the observation was made that there is an inverse association between latitude and skin cancer mortality [15]. In 1980, C. F. Garland and F. C. Garland [16] linked low vitamin D status to a higher risk of colon cancer, based on the theory that vitamin $\mathrm{D}$ is formed in the skin through solar ultraviolet B (UVB) radiation exposure. A similar association between vitamin $\mathrm{D}$ status and breast cancer has since been proposed [4]. It has been demonstrated that geographical incidence and mortality rates of numerous cancers, including breast cancer, are inversely associated with regional UVB radiation exposure [4-9].

The link between the early ecological data showing an inverse relationship between UV radiation exposure and cancer to vitamin D status was the finding that many cell types, including breast cells, contain vitamin D receptors [17]. The theory that vitamin $\mathrm{D}$ may be the factor involved in cancer protection is supported by cell studies showing that vitamin $\mathrm{D}$ induces differentiation and has antiproliferative and proapoptotic effects [18]. The theory is also supported by animal studies showing that vitamin $\mathrm{D}$ reduces tumor growth and size $[19,20]$. Additionally, high serum $25 \mathrm{OHD}$ has been associated with a reduced risk of breast cancer in some [21$23]$ but not all $[24,25]$ studies.

It is well established that exposure to solar UV radiation causes malignant cutaneous melanoma [26]. This seemingly contradictory finding has been explained by the hypothesis that UV exposure to external cells has a mutagenic effect whereas there is a protective effect of UV-induced vitamin $\mathrm{D}$ production on internal cells [27]. As such, cutaneous melanoma incidence could be used as a marker of UV radiation exposure to strengthen the assumption that latitude is inversely associated with UV radiation. Furthermore, the average UV radiation striking the ground has been used as a crude surrogate of vitamin D in epidemiological studies. Although this does not take into account individual behaviors related to sunlight exposure, it has been reported to be a useful marker for vitamin D synthesis [28].

The association between latitude and breast cancer has not been examined in Australia. However, there are reports of an inverse relationship between latitude and malignant cutaneous melanoma and noncutaneous melanoma skin cancer $[29,30]$, with the highest rates of cutaneous melanoma being observed at lower latitudes. That UV radiation exposure is known to cause malignant cutaneous melanoma [31], and it follows that Australian regions with higher rates of cutaneous melanoma are associated with higher UV radiation levels compared to those with lower rates of cutaneous melanoma.

The aim of this study was to examine the association between latitude and incidence of breast cancer and cutaneous melanoma in mainland Australian women.

\section{Methods}

2.1. Breast Cancer and Cutaneous Melanoma Incidence Data. Australia is divided into six states and two territories: New South Wales, Victoria, Queensland, South Australia, Western Australia, Tasmania, the Australian Capital Territory, and Northern Territory (Figure 1). This study was approved by state or territory human research ethics committees (New South Wales Population and Health Services Research Ethics Committee, Queensland Health Human Research Ethics Committee, and Human Research Ethics Committee of Northern Territory Department of Health and Menzies School of Health Research) and/or by written approval from the manager or data custodian of Western Australian, Victorian, and South Australian cancer registries.

Female breast cancer (ICD-10 C50) and cutaneous melanoma (ICD-10 C43.9) counts by 5-year age group (1519 years, 20-24 years, etc., to 85-89 years), for each local government area between 2002 and 2006, were obtained for each state or territory, with the exception of Tasmania for which complete data were not available.

2.2. Population. The Australian 2006 female population, by local government area and 5-year age group, was obtained from the Australian Bureau of Statistics CDATA online database [32]. This was used to calculate age-standardized incidence rates, using the direct method, for breast cancer and cutaneous melanoma. The Australian resident population was used for age standardization.

2.3. Latitude. In latitude, Australia extends from $12^{\circ} \mathrm{S}$ to $43^{\circ} \mathrm{S}$ (Figure 1). The latitude of each local government area was obtained by determining the postcode (zip code) of the most populated town in that local government area or, where all towns were highly populated, the most central town (in latitude) was used.

Latitudes according to postcode were obtained from http://www.corra.com.au/australian-postcode-location-data/. When there was no postcode available, Google Earth (http://www.google.com/earth/index.html) was used to determine the latitude of the most populated town in that local government area. Latitude was grouped into five bands. Due to the plateau effect in age-standardized breast cancer incidence observed at latitudes south of $30^{\circ} \mathrm{S}$, latitude was dichotomized to north or south of $30^{\circ} \mathrm{S}$ in the multiple logistic regression models.

2.4. Index of Relative Socioeconomic Disadvantage. The measure of socioeconomic status and social disadvantage, as discussed in this report, is the Index of Relative Socioeconomic Disadvantage (IRSD). We obtained IRSDs by postcode from the Australian Bureau of Statistics [33]. We used the 


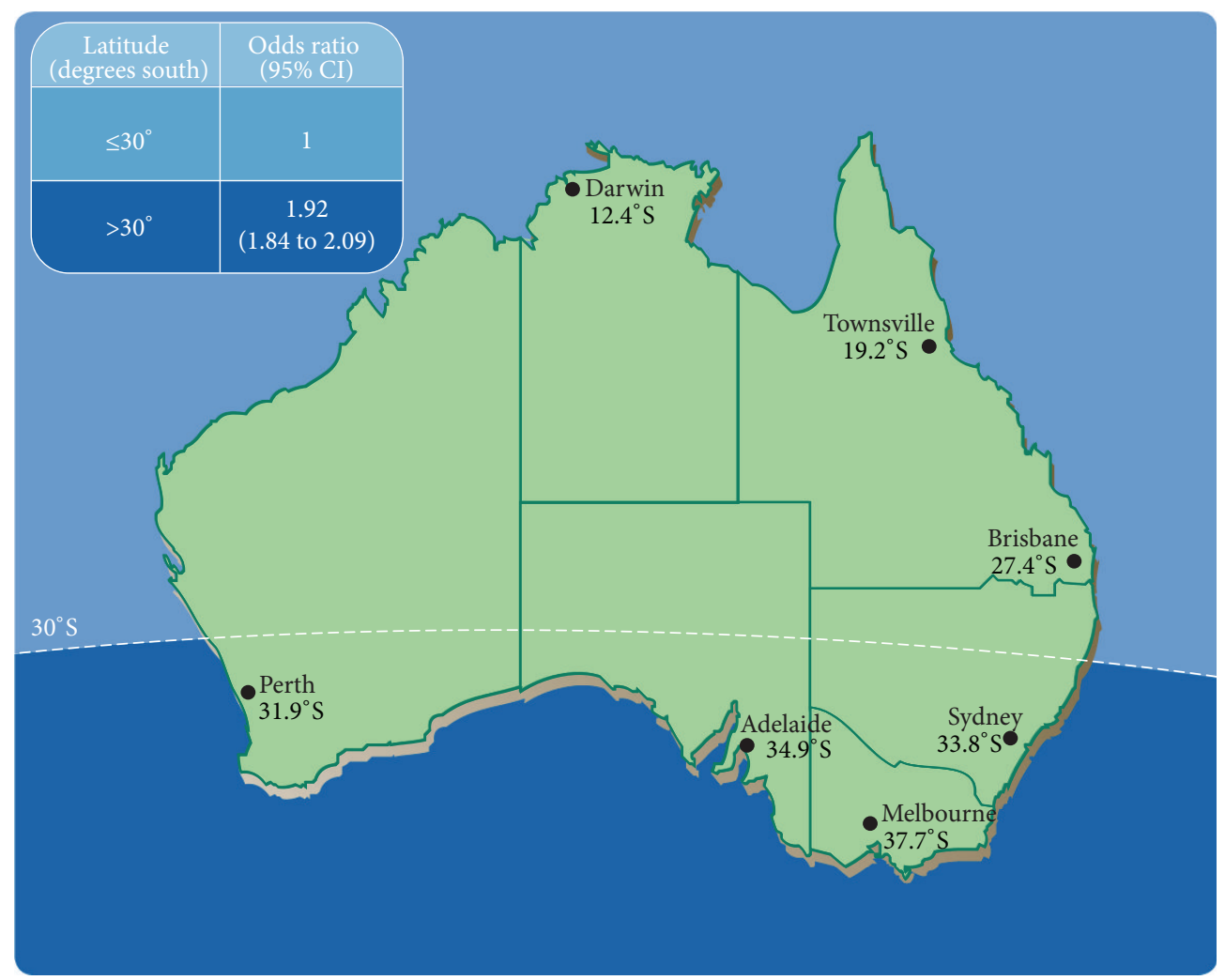

FIGURE 1: Map of Australia showing risk of breast cancer at latitudes south of $30^{\circ} \mathrm{S}$ versus north of $30^{\circ} \mathrm{S}$.

IRSD because it has been shown to be a determinant of vitamin D status [34]. The IRSD focuses on disadvantage and is produced from the Australian national census by the Australian Bureau of Statistics for each postcode using 17 indicators based on education, income, and occupation [35]. We chose to group the IRSD into quintiles for the purpose of our analysis. The lowest IRSD quintile is the most disadvantaged, and the highest quintile is the least disadvantaged. We assigned each local government area an IRSD quintile according to the postcode of the town for which latitude was obtained.

2.5. Accessibility/Remoteness Index of Australia. People living in less accessible regions of Australia are often disadvantaged in their access to health care services. The Accessibility/Remoteness Index of Australia (ARIA) measures remoteness from major metropolitan areas. ARIA values are calculated according to remoteness and based on physical road distance to the nearest urban centre: major cities (ARIA value: $0-0.2)$, inner regional areas $(0.21-2.4)$, outer regional areas (2.41-5.92), remote areas (5.93-10.53), and very remote areas (>10.54). ARIA values were obtained from Australian Bureau of Statistics geographical divisions by postcode [36]. An ARIA was assigned to each local government area according to the postcode of the town for which latitude was obtained. Due to low population numbers and cancer counts, the outer regional, remote, and very remote categories were pooled when assessing the joint effects of several risk factors, using multiple logistic regressions.

2.6. Data Deidentification and Aggregation. Following matching of breast cancer and cutaneous melanoma incidence, population, latitude, postcode, IRSD, and ARIA to each local government area, local government areas were deidentified by removing names and postcodes.

2.7. Statistical Methods and Analysis. The statistical software SPSS version 20.0 (Chicago, IL) was used to analyze the data. Two-tailed tests with a significance level of $5 \%$ were used throughout. Breast cancer incidence rates were age standardized using the direct method, with the mainland Australian female 2006 population as the reference [32].

The age-adjusted odds ratios of breast cancer and associated $95 \%$ confidence intervals ( $95 \% \mathrm{CI}$ ) by latitude band relative to the most northerly band $\left(\leq 27^{\circ} \mathrm{S}\right)$ were calculated within each quintile of IRSD and within each ARIA category. Multiple logistic regression was used to assess the joint effects of latitude band, age group, IRSD, and ARIA category on the incidence of breast cancer and separately for cutaneous melanoma. In order to model the joint effects of several category variables, it was necessary to collapse some of the sparse categories to ensure stable estimates. Specifically, ARIA values were collapsed into three categories (major city, inner regional, and outer regional and beyond), and latitude 
was collapsed into two categories due to the plateau in agestandardized breast cancer incidence observed south of $30^{\circ} \mathrm{S}$.

\section{Results}

Table 1 shows the distribution of breast cancer incidence and population at risk for each latitude band according to decade of age, IRSD quintile, and ARIA category. The age-specific incidence of breast cancer generally increased as latitude and age group increased. The age-standardized incidence of breast cancer was 76.4 at latitudes north of $27^{\circ} \mathrm{S}$, whereas at latitudes south of $30^{\circ} \mathrm{S}$ there was a relative plateau with age-standardized rates approximately doubling to between 160.2 and 176.5. A similar plateau effect was observed within each IRSD quintile and ARIA category, with the age-specific incidences at latitudes south of $30^{\circ} \mathrm{S}$ being approximately twice those at latitudes north of $27^{\circ} \mathrm{S}$. The largest proportion of the population at risk tended to reside between latitudes $27^{\circ} \mathrm{S}$ and $36^{\circ} \mathrm{S}$, be less disadvantaged, and reside in a major city (Table 1).

Within each IRSD quintile and ARIA category, the ageadjusted odds ratios of breast cancer were significantly increased in each latitude band south of $30^{\circ} \mathrm{S}$ compared with north of $27^{\circ} \mathrm{S}(P<0.001$, Table 2$)$. The age-adjusted odds ratio of breast cancer in the most disadvantaged individuals at latitudes between $27^{\circ} \mathrm{S}$ and $30^{\circ} \mathrm{S}$ was almost double the odds ratio at latitudes north of $27^{\circ} \mathrm{S}$ (OR 1.9; 95\% CI 1.2-3.0). The corresponding odds ratio in the second and third IRSD quintiles ranged from 1.2 to 1.5 and failed to reach significance in the two least disadvantaged quintiles. A plateau effect was seen for latitudes south of $30^{\circ} \mathrm{S}$, in which the age-adjusted odds ratio was approximately double that of the reference category (north of $27^{\circ} \mathrm{S}$ ). Similar results were observed within the ARIA categories. At latitudes between $27^{\circ} \mathrm{S}$ and $30^{\circ} \mathrm{S}$, the age-adjusted odds ratios of breast cancer were 1.6 to 1.7 $(P<0.001)$ within the inner and outer regional categories, respectively, but failed to reach significance for the other ARIA categories.

In the multiple logistic regression model, the effect of IRSD and ARIA seen in the age-adjusted analysis was neutralized, in that there were no significant differences between categories within each variable. However, the increased risk of breast cancer remained significant after adjusting for all other variables, in that the OR of breast cancer at latitudes south of $30^{\circ} \mathrm{S}$ was almost double that for latitudes north of $30^{\circ} \mathrm{S}$ (odds ratio: 1.92; 95\% CI: 1.84-2.01; $P<0.001$ ) (Table 3, Figure 1). As expected, the model for cutaneous melanoma also confirmed that after adjusting for age, IRSD, and ARIA, the odds ratio for cutaneous melanoma decreased for latitudes south of $30^{\circ} \mathrm{S}$ compared to latitudes north of $30^{\circ} \mathrm{S}$. This supports the conjecture that latitude is a marker of sunlight exposure, and as latitude increases, the potential for vitamin D synthesis decreases.

\section{Discussion}

A latitudinal gradient has been demonstrated in Australia for several diseases, including multiple sclerosis [37] and diabetes
[38]. This is the first study to show an association between latitude and breast cancer incidence in Australia.

Latitude is an important determinant of vitamin D status [11]. We have shown elsewhere that the potential for vitamin $\mathrm{D}$ synthesis is higher at more northerly locations, compared to more southerly locations in Australia [39]. Additionally, it has been shown that while vitamin $\mathrm{D}$ synthesis can occur throughout the year towards the equator $\left(0^{\circ}\right.$ latitude), at a latitude of $40^{\circ} \mathrm{S}$ (slightly south of Melbourne, VIC (Figure 1)) there is no vitamin D-effective radiation during the winter months $[11,40]$. It is unlikely that dietary intake of vitamin $\mathrm{D}$ accounts for a substantial difference in vitamin $\mathrm{D}$ status in Australians as there are few foods that contain significant amounts of vitamin D. Estimates suggest that Australians consume approximately $80-120 \mathrm{IU}$ vitamin D from foods each day. Additionally, in Australia the only foods that are mandatorily fortified are edible spreads such as table margarines, which contain approximately $40 \mathrm{IU}$ vitamin D per $10 \mathrm{~g}$ serve. There is no data regarding variation in vitamin $\mathrm{D}$ intake by location in which individuals reside, and this is worthy of further investigation. Furthermore, we are unable to explain the plateau effect in age-standardized breast cancer incidence observed at latitudes south of $30^{\circ} \mathrm{S}$, and it may be that there is insufficient vitamin $\mathrm{D}$ synthesis beyond this latitude to have a protective effect.

Our results are in accordance with international studies that show a positive association between risk of, or mortality from, breast cancer and latitude $[2,4,41]$ or measures of inadequate UV radiation $[9,41,42]$. We found that at latitudes south of $30^{\circ} \mathrm{S}$, a line that runs parallel to the equator from north of Perth on the west coast of Australia to approximately midway between Sydney and Brisbane on the east coast of Australia (Figure 1), there was almost double the risk of breast cancer compared with latitudes north of $30^{\circ} \mathrm{S}$. Similarly, a study of 9778 USA Caucasian women aged 20-79 years showed that after adjusting for recognized risk and prognostic factors, mortality rates (per 100000 individuals) among women aged 50-79 years in the west, Midwest, and Northeast were 1.13 (95\% CI, 1.04-1.23), 1.08 (95\% CI, 1.01-1.16), and 1.13 (95\% CI, 1.04 to 1.23 ), respectively, compared to women in the south of the country [2]. Garland et al. also showed a 1.8fold range for breast cancer mortality rates in the USA from the south and southwest to the northeast [4], results that are strikingly similar to ours. Another study, which investigated UVB irradiance in 107 countries, found that age-standardized incidence was substantially higher at latitudes furthest from the equator $\left(R^{2}=0.43 ; P<0.0001\right)$ [9]. Similarly, a study that looked at sunlight levels found a significant negative association between breast cancer incidence rates and sunlight levels $(R=-0.75 ; P=0.001)$ [42].

Our results are in accordance with previous investigations that show higher rates of breast cancer for women from higher socioeconomic status backgrounds (Tables 1-3) [43]. In age-adjusted analysis, we found that women from all IRSD quintiles had at least double the incidence (Table 1) and risk (Table 2) for breast cancer at latitudes south of $30^{\circ} \mathrm{S}$ compared to north of $30^{\circ} \mathrm{S}$ (Tables 1 and 2). There appeared to be an increasing incidence associated with quintile of 


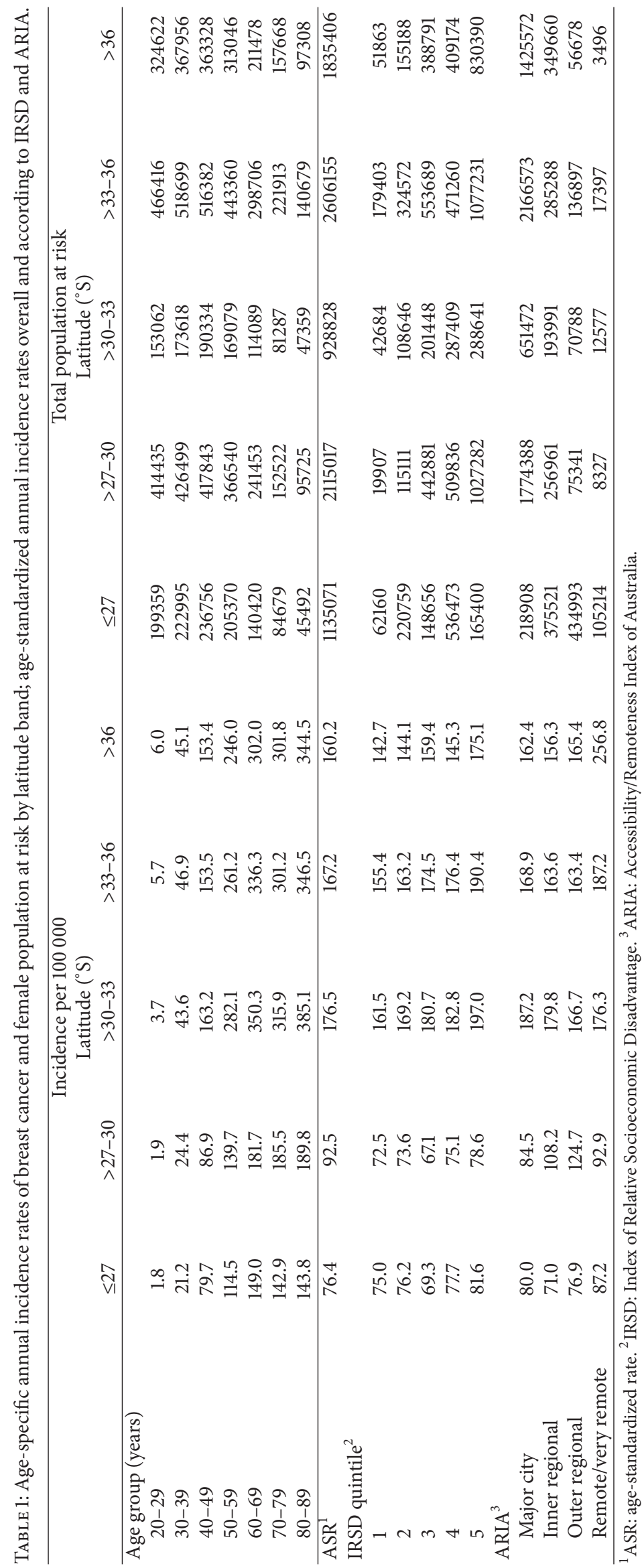


TABLE 2: Age-adjusted odds ratio of breast cancer relative to women at latitude $\leq 27^{\circ} \mathrm{S}$ within each IRSD and ARIA category.

\begin{tabular}{|c|c|c|c|c|c|c|c|c|c|c|}
\hline & \multicolumn{10}{|c|}{ Latitude $\left({ }^{\circ} \mathrm{S}\right)$} \\
\hline & \multicolumn{2}{|c|}{$\leq 27^{1}$} & \multicolumn{2}{|c|}{$27-30$} & \multicolumn{2}{|c|}{$>30-33$} & \multicolumn{2}{|c|}{$>33-36$} & \multicolumn{2}{|l|}{$>36$} \\
\hline & OR & $P$ & OR (95\% CI) & $P$ & OR (95\% CI) & $P$ & OR $(95 \% \mathrm{CI})$ & $P$ & OR $(95 \% \mathrm{CI})$ & $P$ \\
\hline \multicolumn{11}{|l|}{ IRSD $^{2}$ (quintiles) } \\
\hline 1 & 1 & - & $1.9(1.2-3.0)$ & 0.007 & $2.1(1.4-3.0)$ & $<0.001$ & $2.0(1.5-2.8)$ & 0.001 & $1.9(1.3-2.7)$ & $<0.001$ \\
\hline 2 & 1 & - & $1.2(1.0-1.5)$ & 0.103 & $2.2(1.8-2.6)$ & $<0.001$ & $2.1(1.7-2.4)$ & $<0.001$ & $1.9(1.6-2.3)$ & $<0.001$ \\
\hline 3 & 1 & - & $1.5(1.2-1.8)$ & $<0.001$ & $2.5(2.0-3.1)$ & $<0.001$ & $2.3(1.9-2.8)$ & $<0.001$ & $2.3(1.9-2.8)$ & $<0.001$ \\
\hline 4 & 1 & - & $1.1(1.0-1.3)$ & 0.083 & $2.3(2.0-2.6)$ & $<0.001$ & $2.1(1.8-2.4)$ & $<0.001$ & $1.9(1.6-2.1)$ & $<0.001$ \\
\hline 5 & 1 & - & $1.1(0.9-1.3)$ & 0.328 & $2.3(1.9-2.8)$ & $<0.001$ & $2.2(1.9-2.6)$ & $<0.001$ & $2.1(1.8-2.6)$ & $<0.001$ \\
\hline ARIA $^{3}$ & & - & & & & & & & & \\
\hline Major city & 1 & - & $1.1(0.9-1.3)$ & 0.258 & $2.2(1.9-2.6)$ & $<0.001$ & $2.1(1.8-2.4)$ & $<0.001$ & $2.0(1.7-2.3)$ & $<0.001$ \\
\hline Inner regional & 1 & - & $1.6(1.3-1.9)$ & $<0.001$ & $2.4(2.1-2.8)$ & $<0.001$ & $2.3(2.0-2.7)$ & $<0.001$ & $2.2(1.9-2.5)$ & $<0.001$ \\
\hline Outer regional & 1 & - & $1.7(1.3-2.1)$ & $<0.001$ & $2.1(1.7-2.6)$ & $<0.001$ & $2.1(1.8-2.5)$ & $<0.001$ & $2.1(1.7-2.6)$ & $<0.001$ \\
\hline Remote/very remote & 1 & - & $1.1(0.5-2.3)$ & 0.823 & $2.0(1.2-3.2)$ & 0.007 & $2.2(1.4-3.3)$ & $<0.001$ & $2.9(1.4-6.0)$ & 0.006 \\
\hline
\end{tabular}

OR: odds ratio. CI: confidence interval. ${ }^{1}$ Reference category. ${ }^{2}$ IRSD: Index of Relative Socioeconomic Disadvantage. ${ }^{3}$ ARIA: Accessibility/Remoteness Index of Australia. $P$ = significant at $95 \%$ CI.

TABLE 3: Multiple logistic regression models showing odds ratio of breast cancer and of cutaneous melanoma relative to reference category after adjusting for all other variables in the model.

\begin{tabular}{|c|c|c|c|c|}
\hline & \multicolumn{2}{|c|}{ Breast cancer } & \multicolumn{2}{|c|}{ Cutaneous melanoma } \\
\hline & OR (95\% CI) & $P$ & OR $(95 \% \mathrm{CI})$ & $P$ \\
\hline \multicolumn{5}{|l|}{ Age group (years) } \\
\hline $20-29$ & $0.02(0.02-0.03)$ & $<0.001$ & $0.28(0.25-0.32)$ & $<0.001$ \\
\hline $30-39$ & $0.18(0.16-0.19)$ & $<0.001$ & $0.48(0.43-0.53)$ & $<0.001$ \\
\hline $40-49$ & $0.61(0.58-0.64)$ & $<0.001$ & $0.70(0.64-0.77)$ & $<0.001$ \\
\hline $50-59^{1}$ & 1.00 & & 1.00 & \\
\hline $60-69$ & $1.27(1.21-1.34)$ & $<0.001$ & $1.35(1.24-1.47)$ & $<0.001$ \\
\hline $70-79$ & $1.20(1.14-1.28)$ & $<0.001$ & $1.81(1.66-1.98)$ & $<0.001$ \\
\hline $80-89$ & $1.36(1.27-1.45)$ & $<0.001$ & $1.74(1.57-1.93)$ & $<0.001$ \\
\hline \multicolumn{5}{|l|}{ IRSD $^{2}$ (quintiles) } \\
\hline 1 & 1.00 & & 1.00 & \\
\hline 2 & $0.99(0.89-1.10)$ & 0.824 & $1.16(0.98-1.38)$ & 0.087 \\
\hline 3 & $1.07(0.97-1.18)$ & 0.158 & $1.29(1.10-1.52)$ & 0.002 \\
\hline 4 & $1.03(0.94-1.14)$ & 0.521 & $1.28(1.09-1.51)$ & 0.003 \\
\hline 5 & $1.16(1.05-1.27)$ & 0.003 & $1.39(1.18-1.63)$ & $<0.001$ \\
\hline \multicolumn{5}{|l|}{ ARIA $^{3}$} \\
\hline Major city ${ }^{1}$ & 1.00 & & 1.00 & \\
\hline Inner regional & $1.03(0.98-1.08)$ & 0.289 & $1.30(1.20-1.39)$ & $<0.001$ \\
\hline Outer regional and beyond & $1.05(0.98-1.13)$ & 0.136 & $1.16(1.06-1.28)$ & 0.001 \\
\hline \multicolumn{5}{|l|}{ Latitude } \\
\hline$\leq 30^{\circ} \mathrm{S}^{1}$ & 1.00 & & 1.00 & \\
\hline$>30^{\circ} \mathrm{S}$ & $1.92(1.84-2.01)$ & $<0.001$ & $0.65(0.61-0.68)$ & $<0.001$ \\
\hline
\end{tabular}

OR: odds ratio. CI: confidence interval. ${ }^{1}$ Reference category. ${ }^{2}$ IRSD: Index of Relative Socioeconomic Disadvantage. ${ }^{3}$ ARIA: Accessibility/Remoteness Index of Australia. $\boldsymbol{P}=$ significant at $95 \% \mathrm{CI}$.

socioeconomic disadvantage for each latitude band (Table 1) although no effect after adjusting for age was seen (Table 2). However, after adjusting for age group, ARIA, and latitude, only those in the highest quintile had a significantly higher risk of breast cancer (OR: 1.16; 95\% CI: 1.05-1.27; $P=0.003$ ) (Table 3 ). It is possible that factors that we have not been able to control for, such as diet, physical activity, body mass index, parity, and hormone use, for example, explain the association we have seen as these factors are known to affect breast cancer risk [44-46]. There is little data available on such factors according to latitude or location of residence of women in Australia. Additionally, variations in screening rates across Australia may account for the association we have observed. For instance, women who reside in remote areas 
may not have the same access to screening programs as those in major cities. Our ability to control for remoteness may somewhat control for such variation; however it is possible that residual confounding occurs. These factors are worthy of further investigation.

Findings on the relationship between breast cancer and remoteness have been inconsistent. In age-adjusted analysis, we found that women from all remoteness quintiles had a similar risk of 2 or above for breast cancer at latitudes south of $30^{\circ} \mathrm{S}$, although there was no effect of major city, as shown by similar incidence and risk among categories of remoteness (Tables 1 and 2). Similarly, after adjusting for age, socioeconomic disadvantage, and latitude, we found a similar risk of breast cancer, irrespective of whether subjects resided in a major city, inner regional area, or outer regional area and beyond (Table 3). These findings are in accordance with a study by the English, [47] which showed no statistically significant differences in breast cancer risk by remoteness. Conversely, reports from the Australian Institute of Health and Welfare show that those residing in major cities or inner regional areas had significantly higher 5 -year relative survival (both 88\%) than those from outer regional areas (85\%) [43]. These opposing findings in that report may be caused by a confounding effect of latitude, which was not adjusted for in the Australian Institute of Health and Welfare study.

A weakness of our study is that we were unable to take into account individual serum $25(\mathrm{OH}) \mathrm{D}$ concentrations or the factors that affect vitamin D concentration, such as sunlight exposure, obesity, age, and skin pigmentation [48]. The strengths of our study include our ability to control for age, socioeconomic disadvantage, and distance from a major city, all of which have been shown to be important determinants of vitamin D status [34].

The association of cutaneous melanoma with increasing UV radiation exposure and lower latitudes at closer proximity to the equator has been well documented internationally $[49,50]$ and in Australia, $[29,30]$ and is in accordance with our finding that the risk of cutaneous melanoma is lower at latitudes south of $30^{\circ} \mathrm{S}$ compared with north of $30^{\circ} \mathrm{S}$. However, as has been suggested [40], it is possible that latitude alone is not a good indicator of vitamin D status since other factors such as cloud cover and ozone affect vitamin D synthesis. Nevertheless, our finding that the risk of cutaneous melanoma decreases as latitude increases supports the notion that UV radiation levels decrease with increasing latitude, and therefore the potential for vitamin D synthesis also decreases as latitude increases.

In summary our data show that living at higher latitudes towards the south of Australia, in particular at more than $30^{\circ} \mathrm{S}$, is associated with a significantly increased risk of breast cancer compared to latitudes less than $30^{\circ} \mathrm{S}$. Further, in multivariate analysis, we showed that the major city effect did not make a difference, but factors such as high socioeconomic status were independently associated with an increased risk of breast cancer.

Our data add to previous ecological evidence suggesting a relationship between latitude and breast cancer incidence, although confounding effects from other factors cannot be totally excluded. Our findings should be interpreted with caution; they cannot imply causation of breast cancer by low vitamin D as the link between latitude, UV radiation, and vitamin $\mathrm{D}$ remains speculative. Further studies involving direct measurement of serum vitamin $\mathrm{D}$ are needed to directly test this hypothesis.

\section{Abbreviations}

ARIA: Accessibility/Remoteness Index of Australia

IRSD: Index of Relative Socioeconomic Disadvantage.

\section{Conflict of Interests}

The authors declare that there is no conflict of interests regarding the publication of this paper.

\section{Acknowledgments}

The authors wish to acknowledge the data custodians and information managers of individual states and territories for kindly providing the data and Katherine Hart for preparing the figure. This work was supported by internal research funding from Westmead Breast Cancer Institute.

\section{References}

[1] W. J. Blot, J. F. Fraumeni Jr., and B. J. Stone, "Geographic patterns of breast cancer in the United States," Journal of the National Cancer Institute, vol. 59, no. 5, pp. 1407-1411, 1977.

[2] S. R. Sturgeon, C. Schairer, M. Gall, M. McAdams, L. A. Brinton, and R. N. Hoover, "Geographic variation in mortality from breast cancer among white women in the United States," Journal of the National Cancer Institute, vol. 87, no. 24, pp. 1846-1853, 1995.

[3] S. B. Mohr, C. F. Garland, E. D. Gorham, W. B. Grant, and F. C. Garland, "Ultraviolet B irradiance and incidence rates of bladder cancer in 174 countries," The American Journal of Preventive Medicine, vol. 38, no. 3, pp. 296-302, 2010.

[4] F. C. Garland, C. F. Garland, E. D. Gorham, and J. F. Young, "Geographic variation in breast cancer mortality in the United States: a hypothesis involving exposure to solar radiation," Preventive Medicine, vol. 19, no. 6, pp. 614-622, 1990.

[5] W. B. Grant and C. F. Garland, "The association of solar ultraviolet B (UVB) with reducing risk of cancer: multifactorial ecologic analysis of geographic variation in age-adjusted cancer mortality rates," Anticancer Research, vol. 26, no. 4A, pp. 26872699, 2006.

[6] F. P. Boscoe and M. J. Schymura, "Solar ultraviolet-B exposure and cancer incidence and mortality in the United States, 19932002," BMC Cancer, vol. 6, article 264, 2006.

[7] W. Chen, M. Clements, B. Rahman, S. Zhang, Y. Qiao, and B. K. Armstrong, "Relationship between cancer mortality/incidence and ambient ultraviolet B irradiance in China," Cancer Causes and Control, vol. 21, no. 10, pp. 1701-1709, 2010.

[8] D. M. Freedman, M. Dosemeci, and K. McGlynn, "Sunlight and mortality from breast, ovarian, colon, prostate, and nonmelanoma skin cancer: a composite death certificate based casecontrol study," Occupational and Environmental Medicine, vol. 59, no. 4, pp. 257-262, 2002. 
[9] S. B. Mohr, C. F. Garland, E. D. Gorham, W. B. Grant, and F. C. Garland, "Relationship between low ultraviolet B irradiance and higher breast cancer risk in 107 countries," Breast Journal, vol. 14, no. 3, pp. 255-260, 2008.

[10] M. F. Holick, "Sunlight and vitamin D for bone health and prevention of autoimmune diseases, cancers, and cardiovascular disease," The American Journal of Clinical Nutrition, vol. 80, no. 6, pp. 1678S-1688S, 2004.

[11] A. R. Webb, L. Kline, and M. F. Holick, "Influence of season and latitude on the cutaneous synthesis of vitamin D3: exposure to winter sunlight in Boston and Edmonton will not promote vitamin D3 synthesis in human skin," Journal of Clinical Endocrinology and Metabolism, vol. 67, no. 2, pp. 373-378, 1988.

[12] R. M. Daly, C. Gagnon, Z. X. Lu et al., "Prevalence of vitamin $\mathrm{D}$ deficiency and its determinants in Australian adults aged 25 years and older: a national, population-based study," Clinical Endocrinology, vol. 77, no. 1, pp. 26-35, 2012.

[13] S. Boyages and K. Bilinski, "Seasonal reduction in vitamin D level persists into spring in NSW Australia: implications for monitoring and replacement therapy," Clinical Endocrinology, vol. 77, no. 4, pp. 515-523, 2012.

[14] S. Peller and C. S. Stephenson, "Skin irritation and cancer in the United States Navy," The American Journal of the Medical Sciences, vol. 194, pp. 326-333, 1937.

[15] F. L. Apperly, "The relation of solar radiation to cancer mortality in North America," Cancer Research, vol. 1, pp. 191-195, 1941.

[16] C. F. Garland and F. C. Garland, "Do sunlight and vitamin D reduce the likelihood of colon cancer?” International Journal of Epidemiology, vol. 9, no. 3, pp. 227-231, 1980.

[17] R. R. Buras, L. M. Schumaker, F. Davoodi et al., "Vitamin D receptors in breast cancer cells," Breast Cancer Research and Treatment, vol. 31, no. 2-3, pp. 191-202, 1994.

[18] K. W. Colston and C. M. Hansen, "Mechanisms implicated in the growth regulatory effects of vitamin D in breast cancer," Endocrine-Related Cancer, vol. 9, no. 1, pp. 45-59, 2002.

[19] K. W. Colston, R. C. Coombes, and U. Berger, "Possible role for vitamin $\mathrm{D}$ in controlling breast cancer cell proliferation," The Lancet, vol. 1, no. 8631, pp. 188-191, 1989.

[20] L. L. Ooi, Y. Zheng, K. Stalgis-Bilinski, and C. R. Dunstan, "The bone remodeling environment is a factor in breast cancer bone metastasis," Bone, vol. 48, no. 1, pp. 66-70, 2011.

[21] E. R. Bertone-Johnson, W. Y. Chen, M. F. Holick et al., "Plasma 25-hydroxyvitamin D and 1,25-dihydroxyvitamin D and risk of breast cancer," Cancer Epidemiology, Biomarkers \& Prevention, vol. 14, no. 8, pp. 1991-1997, 2005.

[22] C. F. Garland, E. D. Gorham, S. B. Mohr, and F. C. Garland, "Vitamin D for cancer prevention: global perspective," Annals of Epidemiology, vol. 19, no. 7, pp. 468-483, 2009.

[23] K. Bilinski and J. Boyages, "Association between 25-hydroxyvitamin D concentration and breast cancer risk in an Australian population: an observational case-control study," Breast Cancer Research and Treatment, vol. 137, no. 2, pp. 599-607, 2013.

[24] M. L. Neuhouser, J. E. Manson, A. Millen et al., "The influence of health and lifestyle characteristics on the relation of serum 25-hydroxyvitamin D with risk of colorectal and breast cancer in postmenopausal women," American Journal of Epidemiology, vol. 175, no. 7, pp. 673-684, 2012.

[25] E. Amir, R. S. Cecchini, P. A. Ganz et al., "25-Hydroxy vitamin$\mathrm{D}$, obesity, and associated variables as predictors of breast cancer risk and tamoxifen benefit in NSABP-P1," Breast Cancer Research and Treatment, vol. 133, no. 3, pp. 1077-1088, 2012.
[26] B. K. Armstrong and A. Kricker, "Skin cancer," Dermatologic Clinics, vol. 13, no. 3, pp. 583-594, 1995.

[27] G. P. Yu, D. N. Hu, and S. A. McCormick, "Latitude and incidence of ocular melanoma," Photochemistry and Photobiology, vol. 82, no. 6, pp. 1621-1626, 2006.

[28] E. Giovannucci, "The epidemiology of vitamin D and cancer incidence and mortality: a review (United States)," Cancer Causes and Control, vol. 16, no. 2, pp. 83-95, 2005.

[29] C. D. J. Holman, I. R. James, P. H. Gattey, and B. K. Armstrong, "An analysis of trends in mortality from malignant melanoma of the skin in Australia," International Journal of Cancer, vol. 26, no. 6, pp. 703-709, 1980.

[30] M. P. Staples, M. Elwood, R. C. Burton, J. L. Williams, R. Marks, and G. G. Giles, "Non-melanoma skin cancer in Australia: the 2002 national survey and trends since 1985," Medical Journal of Australia, vol. 184, no. 1, pp. 6-10, 2006.

[31] B. K. Armstrong and A. Kricker, "The epidemiology of UV induced skin cancer," Journal of Photochemistry and Photobiology B: Biology, vol. 63, no. 1-3, pp. 8-18, 2001.

[32] Australian Bureau of Statistics (ABS), CDATA: Australian Population by Age and Sex, Australian Bureau of Statistics, 2006, https://www.censusdata.abs.gov.au/CDATAOnline.

[33] Australian Bureau of Statistics (ABS), Census of Population and Housing: Socio-Economic Indexes for Areas (SEIFA), Australian Bureau of Statistics, Melbourne, Australia, 2006.

[34] S. Boyages and K. Bilinski, "Seasonal reduction in vitamin D level persists into spring in NSW Australia: implications for monitoring and replacement therapy," Clinical Endocrinology, vol. 77, no. 4, pp. 515-523, 2012.

[35] B. Pink, Information Paper: An Introduction to Socio-Economic Indexes for Areas (SEIFA), Australian Bureau of Statistics, Canberra, Australia, 2006.

[36] Australian Bureau of Statistics (ABS), Australian Standard Geographical Classification (ASGC) Remoteness Area Correspondences, 2006, Australian Bureau of Statistics, 2008.

[37] D. H. Miller, S. R. Hammond, J. G. McLeod, G. Purdie, and D. C. Skegg, "Multiple sclerosis in Australia and New Zealand: are the determinants genetic or environmental?" Journal of Neurology, Neurosurgery, and Psychiatry, vol. 53, no. 10, pp. 903-905, 1990.

[38] J. A. Staples, A. L. Ponsonby, L. L. Lim, and A. J. McMichael, "Ecologic analysis of some immune-related disorders, including type 1 diabetes, in Australia: latitude, regional ultraviolet radiation, and disease prevalence," Environmental Health Perspectives, vol. 111, no. 4, pp. 518-523, 2003.

[39] K. L. Stalgis-Bilinski, J. Boyages, E. L. Salisbury, C. R. Dunstan, S. I. Henderson, and P. L. Talbot, "Burning daylight: balancing vitamin D requirements with sensible sun exposure," Medical Journal of Australia, vol. 194, no. 7, pp. 345-348, 2011.

[40] M. G. Kimlin, "Geographic location and vitamin D synthesis," Molecular Aspects of Medicine, vol. 29, no. 6, pp. 453-461, 2008.

[41] W. B. Grant, "An ecologic study of dietary and solar ultravioletB links to breast carcinoma mortality rates," Cancer, vol. 94, no. 1, pp. 272-281, 2002.

[42] E. D. Gorham, F. C. Garland, and C. F. Garland, "Sunlight and breast cancer incidence in the USSR," International Journal of Epidemiology, vol. 19, no. 4, pp. 820-824, 1990.

[43] Australian Institute of Health and Welfare \& Cancer Australia, Breast Cancer in Australia: An Overview, Cancer Series no. 71, Cat. no. CAN 67, AIHW, Canberra, Australia, 2012.

[44] L. H. Kushi, M. L. Kwan, M. M. Lee, and C. B. Ambrosone, "Lifestyle factors and survival in women with breast cancer," Journal of Nutrition, vol. 137, no. 1, pp. 236S-242S, 2007. 
[45] R. Chlebowski, "Lifestyle change including dietary fat reduction and breast cancer outcome," Journal of Nutrition, vol. 137, no. 1, pp. 233S-235S, 2007.

[46] C. L. Rock and W. Demark-Wahnefried, "Can lifestyle modification increase survival in women diagnosed with breast cancer?" Journal of Nutrition, vol. 132, supplement 11, pp. 3504S-3507S, 2002.

[47] D. R. English, H. Farrugia, V. Thursfield, P. Chang, and G. G. Giles, Cancer Survival Victoria 2007: Estimates of Survival in 2004 (and Comparisons with Earlier Periods), The Cancer Council Victoria, Melbourne, Australia, 2007.

[48] M. F. Holick, "High prevalence of vitamin D inadequacy and implications for health," Mayo Clinic Proceedings, vol. 81, no. 3, pp. 353-373, 2006.

[49] S. Gandini, F. Sera, M. S. Cattaruzza et al., "Meta-analysis of risk factors for cutaneous melanoma: II. Sun exposure," European Journal of Cancer, vol. 41, no. 1, pp. 45-60, 2005.

[50] J. Moan, A. C. Porojnicu, and A. Dahlback, "Ultraviolet radiation and malignant melanoma," Advances in Experimental Medicine and Biology, vol. 624, pp. 104-116, 2008. 


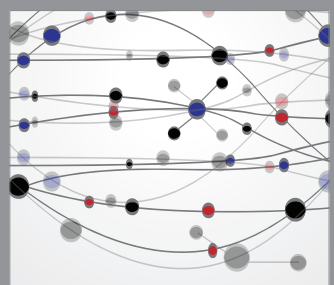

The Scientific World Journal
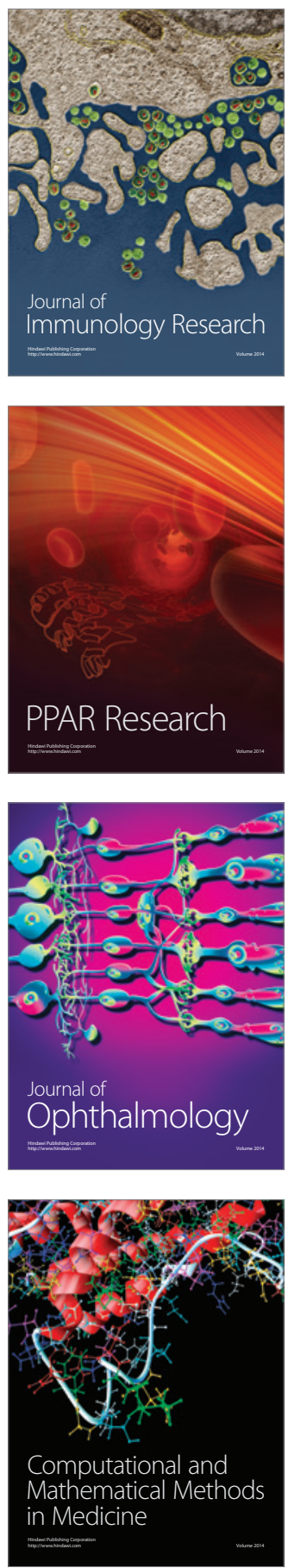

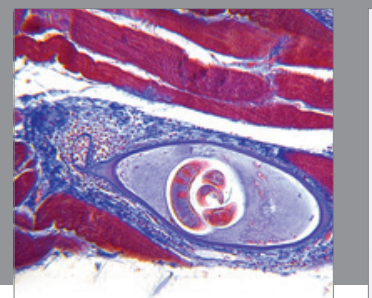

Gastroenterology

Research and Practice
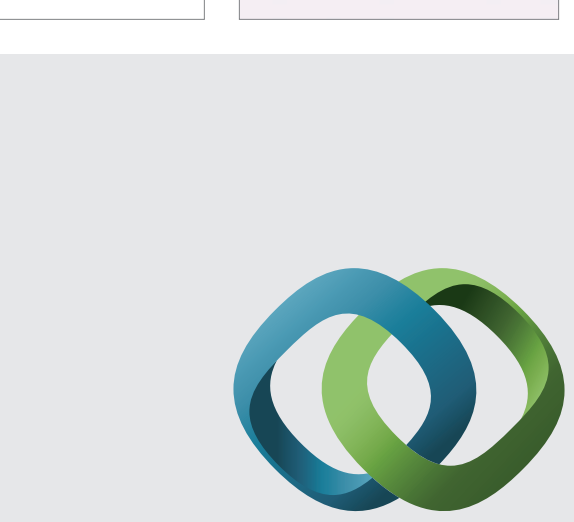

\section{Hindawi}

Submit your manuscripts at

http://www.hindawi.com
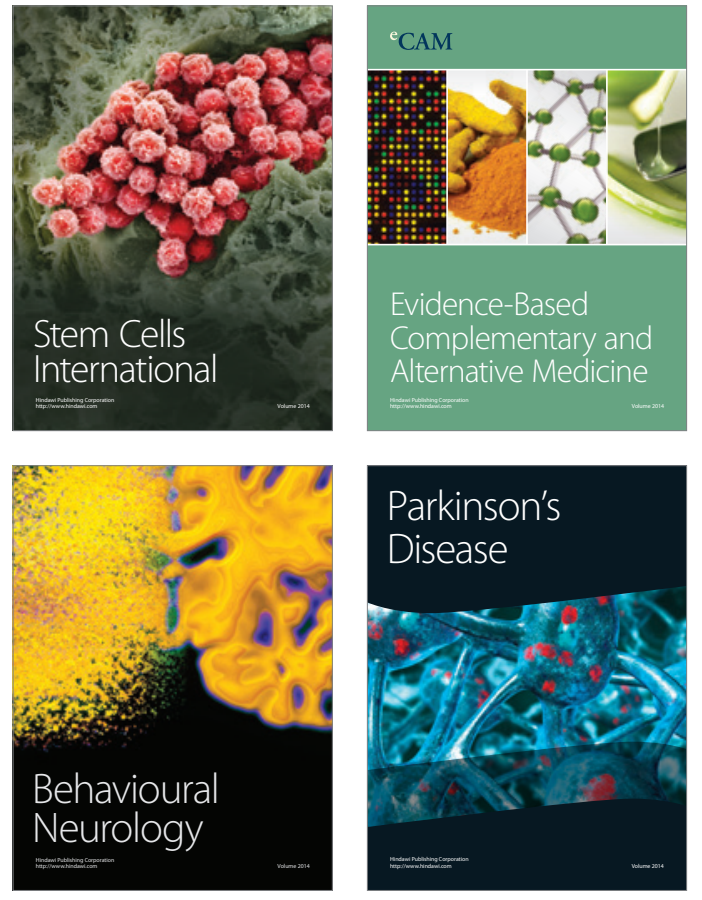
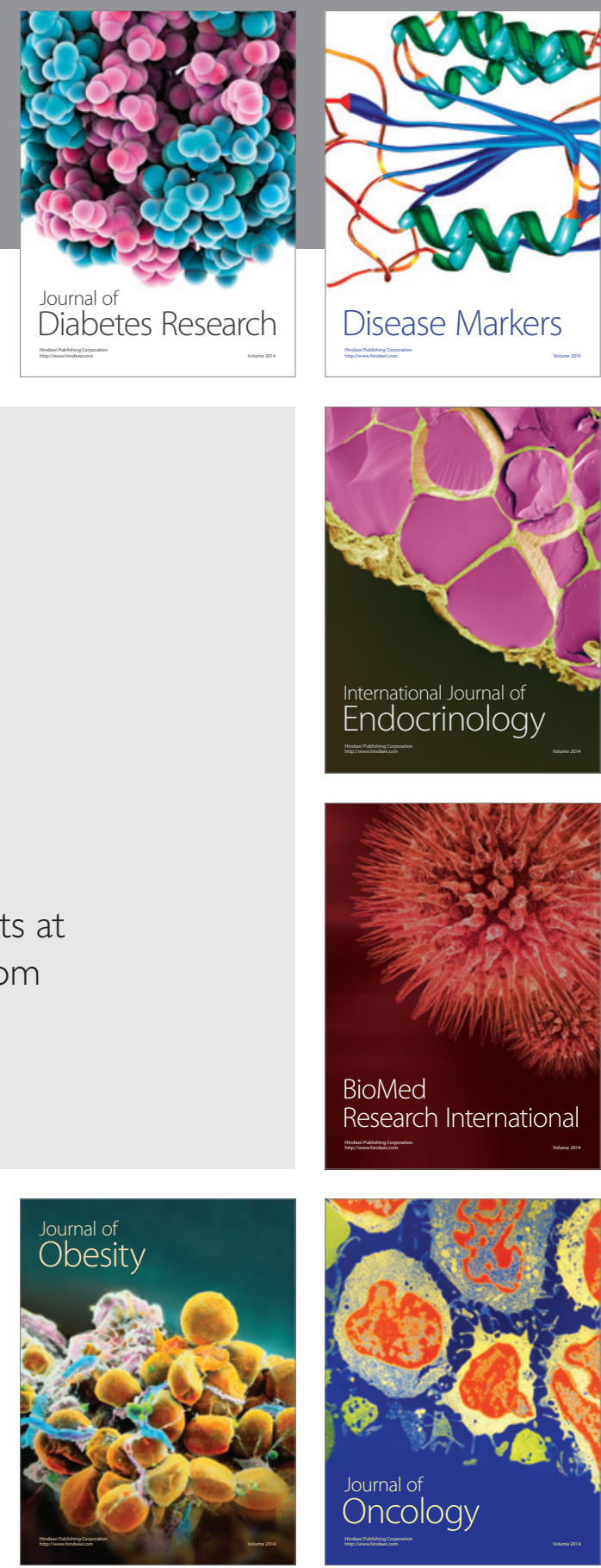

Disease Markers
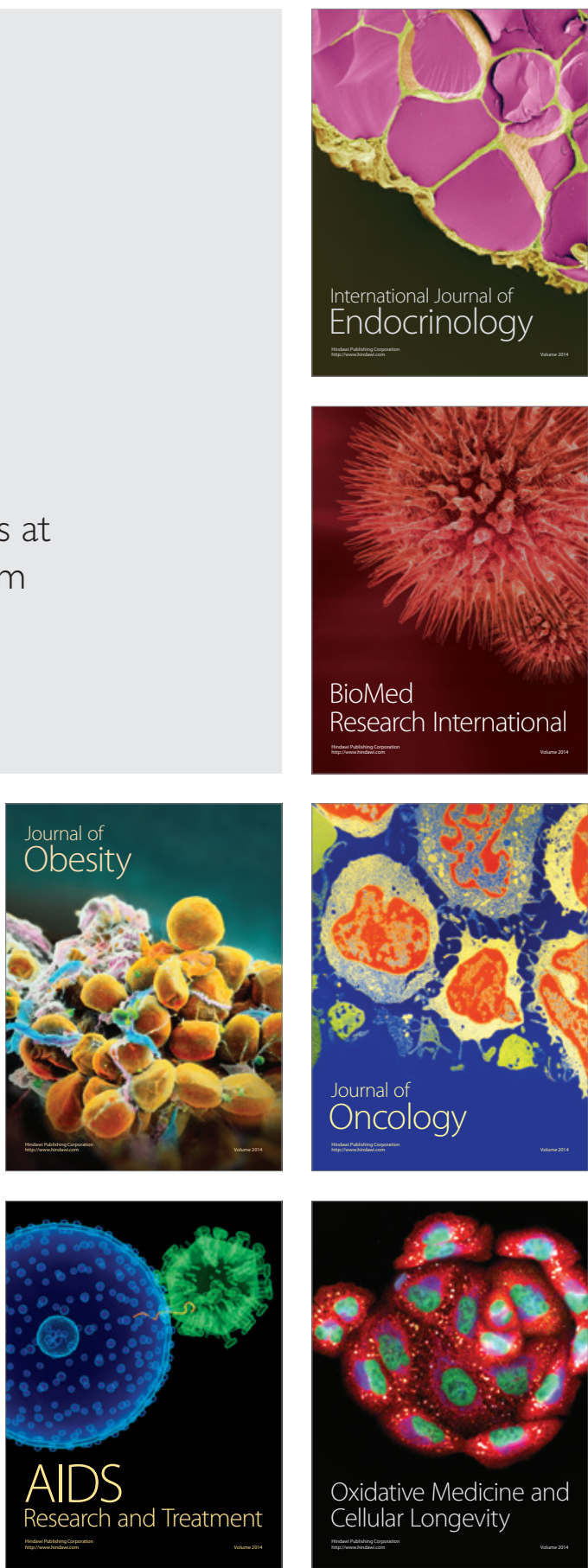